\title{
Visual Metaphors: Howardena Pindell, Video Drawings, 1975
}

\author{
Niccolò Tempini
}

Abstract Closing reflections on data journeys through the contemplative reading of a visual work by Howardena Pindell.

As Grace Deveney reports (2018), ${ }^{1}$ the series Video Drawings came together when feminist African American artist, curator and educator Howardena Pindell took a sheet of acetate and drew signs, arrows and numbers upon it. Then she hung it on her television screen, taking advantage of the static that glues the light plastic to the screen glass. Using a camera, she took photographs of the transient juxtapositions that formed in front of her. Finally, she selected the set of most interesting combinations from the lot, including "those that had a "weird" sense of movement" (153).

\footnotetext{
${ }^{1}$ Deveney, Grace. 2018. Interrupting the Broadcast: Howardena Pindell's Video Drawings. In Howardena Pindell: What Remains to Be Seen, Beckwith, Naomi and Cassel Oliver, Valerie (eds.), 151-168. Munich: DelMonico Books-Prestel \& Museum of Contemporary Art Chicago.
}

\section{N. Tempini $(\triangle)$}

Department of Sociology, Philosophy and Anthropology \& Exeter Centre for the Study of the Life Sciences (Egenis), Exeter, UK

Alan Turing Institute, London, UK

e-mail: n.tempini@exeter.ac.uk 


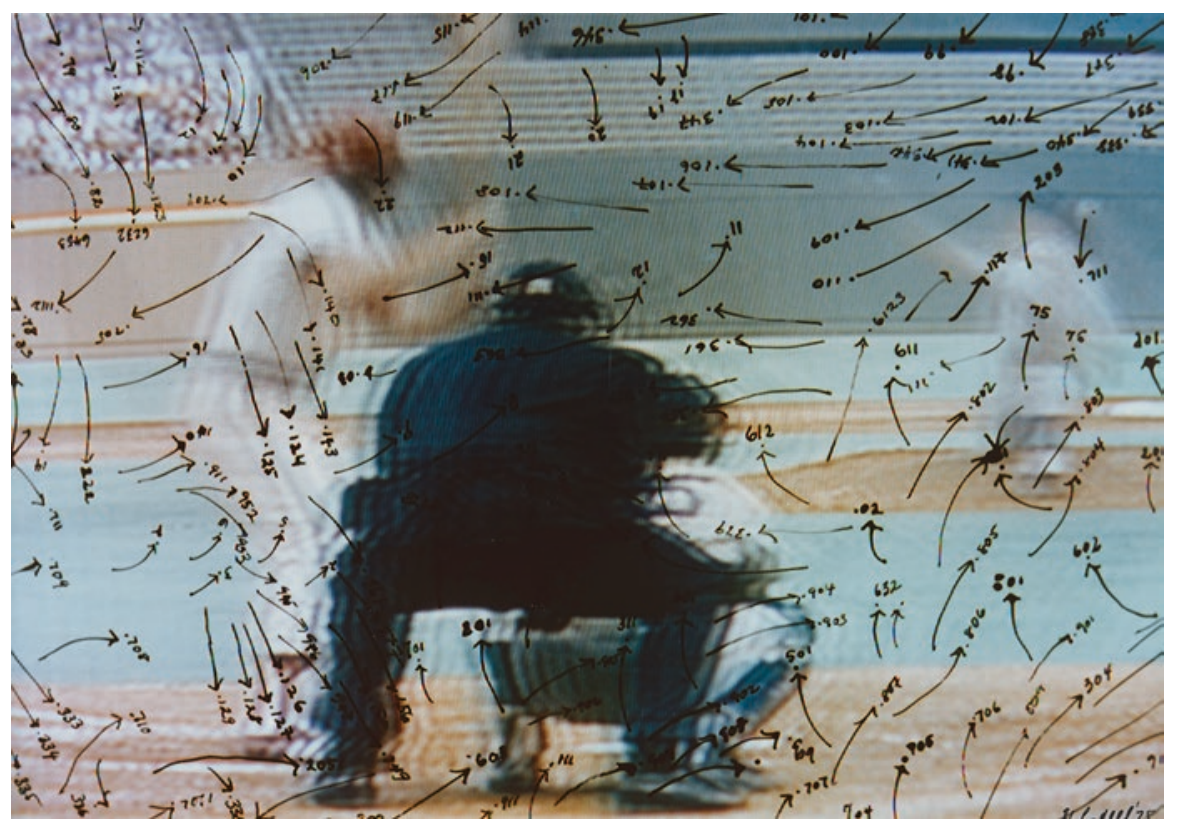

Untitled (Video Drawing: Baseball Series), August, 1975. Chromogenic color print (Pindell, Howardena (b. 1943): Untitled (Video Drawing: Baseball Series), August, 1975. Chromogenic color print, 4 5/8 $\times 67 / 8^{\prime \prime}(11.7 \times 16.7 \mathrm{~cm})$. Purchase. Acc. no.: 276.1976. New York, Museum of Modern Art (MoMA). (C) 2019. Digital image, The Museum of Modern Art, New York/Scala, Florence. Courtesy the artist and Garth Greenan Gallery, New York.)

This Video Drawings work might speak as any other picture to the reflections about data and science practices that have been shared in this book. So many lines could be pursued that my few words here might sound arbitrary. I share them to invite, not to foreclose.

By juxtaposing notations to image Pindell prefigures something of data practices and analytics - "They resemble weather movement notations, dance notations, and particle tracks" (162). But just as with data, there is nothing obvious about them.

Let me first point out a few parallels, starting from the most immediate - Video Drawings is a curated collection of stills, selecting the compelling and the surprising. Highlighting some at the expense of others, the artist had to make certain assumptions consequential that shape the nature of what is shared with others and add explicit intention to an experiment. More interestingly, the works organised in this set are visual juxtapositions. They exploit the predilections of some materials to work together, and in so doing they facilitate the linking with one another of two heterogeneous records. The TV image becomes something else, as it is transformed by Pindell's re-purposing practices. Through the stilling of the moving image in a 
photograph, a record of bodily and material configurations has been extracted (cfr. The digital 'scraped') from material released for public consumption rather than careful analysis - the broadcast of a sport performance. Like data, these are objects that can be repeatedly discovered to reveal something new. Their circulation can restart.

Deveney (2018) points out how the Video Drawings juxtaposition eventually collapses the original image, erasing distinctions between foreground and background, body and field. The low resolution of the TV screenshot makes us think of instruments pushed to the limits. It makes us wonder about the fragility of the processes with which data can be put to previously unimagined uses. The visual record is rescued from a rather adventurous path of transmission and yet, for all the loss of detail in the grainy still, other, new information seems to emerge in the juxtaposition with the acetate sheet. The artist, presumed spectator of the TV stream, reclaims a role and intervenes, highlighting the creative opportunities opened by constraints and omissions. New links are suggested, various relations between data points can be postulated. But the juxtaposition remains ultimately open-ended as to its most important message. Consensus remains controvertible, and several narratives might successfully navigate the visual space. The acetate sheet, with its pre-recorded content, seems to suggest the existence of frameworks and assumptions enabling and structuring ways of reading the record, which are now lost history. The drawn notations are not analysis of the picture themselves, but could they be abstractions obtained from other analyses? At least they seem available to participate in one.

Yet, for all the stimulation it offers, the composition refuses to promise that any new meaning can be found. As Deveney observes (2018), the composition hangs between order and chaos, predictability and randomness. It might not be what it seems. It remains unclear what its final use or destination might be. In this suspension, the work reminds us of many steps of data journeys that we have discussed in this book - somewhere between the past moment of generation and the future moment of definite interpretation.

Niccolò Tempini is Senior Lecturer in Data Studies at the University of Exeter, Department of Sociology, Philosophy and Anthropology, and a Turing Fellow at the Alan Turing Institute. He is an interdisciplinary social scientist interested in questions of information, data, technology, organization, value and knowledge. He researches Big Data research and digital infrastructures, investigating the specific knowledge production economies, organization forms and data management innovations that these projects engender with a focus in their social and epistemic consequences. He studies the practices of data scientists, software developers, researchers and nonprofessionalised experts to understand how different forms of knowledge and value intersect with each other when different actors come to grips with new methods and new forms of data, information technology and organization. His research has been published in international journals across science and technology studies, information systems, sociology and philosophy (more information at www. tempini.info). 
Open Access This chapter is licensed under the terms of the Creative Commons Attribution 4.0 International License (http://creativecommons.org/licenses/by/4.0/), which permits use, sharing, adaptation, distribution and reproduction in any medium or format, as long as you give appropriate credit to the original author(s) and the source, provide a link to the Creative Commons license and indicate if changes were made.

The images or other third party material in this chapter are included in the chapter's Creative Commons license, unless indicated otherwise in a credit line to the material. If material is not included in the chapter's Creative Commons license and your intended use is not permitted by statutory regulation or exceeds the permitted use, you will need to obtain permission directly from the copyright holder. 